\title{
Droop Control of Distributed Electric Springs for Stabilizing Future Power Grid
}

\author{
C.K. Lee, Member, IEEE, N.R. Chaudhuri, Member, IEEE, B. Chaudhuri, Senior Member, IEEE, and \\ S.Y.(Ron) Hui, Fellow, IEEE
}

\begin{abstract}
This paper describes the droop control method for parallel operation of distributed electric springs for stabilizing ac power grid. It provides a methodology that has the potential of allowing reactive power controllers to work in different locations of the distribution lines of an ac power supply and for these reactive power controllers to support and stabilize the ac mains voltage levels at their respective locations on the distribution lines. The control scheme allows these reactive power controllers to have automatically adjustable voltage references according to the mains voltage levels at the locations of the distribution network. The control method can be applied to reactive power controllers embedded in smart electric loads distributed across the power grid for stabilizing and supporting the ac power supply along the distribution network. The proposed distributed deployment of electric springs is envisaged to become an emerging technology potentially useful for stabilizing power grids with substantial penetration of distributed and intermittent renewable power sources or weakly regulated ac power grid.
\end{abstract}

Index Terms - Smart Gird, Droop Control, Electric Springs, Voltage regulation.

\section{INTRODUCTION}

$\mathrm{I}$ $\mathrm{N}$ traditional power systems, the power flow is controlled by the power plants and with the power generation following the load demand on an instantaneous basis. The power flow is centrally controlled by the utility companies and is essentially carried out in a unidirectional manner. In future power grids, increasing proportion of renewable energy sources such as wind and solar energy systems will be installed in a distributed fashion across the load centers (and thus all over the power grids). These distributed renewable energy sources may be known or unknown to the utility companies and a significant portion of them are to be connected to the distribution network close to the loads. Since

Manuscript received August 28, 2012. This work was supported in part by the EPSRC (grant no. EP/F029128/1), the Hong Kong Research Grant Council under Grant HKU10/CRG/10 and the University of Hong Kong Seed Funds (Seed Projects: 201111159239 \& 201203159010).

C.K. Lee is with the Department of Electrical \& Electronic Engineering, The University of Hong Kong (e-mail: cklee@eee.hku.hk).

N. Chaudhuri was with the Department of Electrical \& Electronic Engineering, Imperial College London and is now with the General Electric, USA (e-mail: nilanjgec@gmail.com).

B. Chaudhuri is with the Department of Electrical \& Electronic Engineering, Imperial College London (e-mail: b.chaudhuri@imperial.ac.uk).

S.Y.R. Hui is with the Department of Electrical \& Electronic Engineering, The University of Hong Kong (e-mail: ronhui@eee.hku.hk) and also with Imperial College London (e-mail: r.hui@imperial.ac.uk). it is not possible to determine the total instantaneous power generation from distributed renewable sources since they are non-dispatchable, the increasing use of intermittent renewable energy sources is expected to introduce dynamic instability to the ac power supply, potentially resulting in highly fluctuating or even unstable ac mains voltage [1]. In future power grids, a new control paradigm is needed to ensure that the load demand should follow the power generation [2],[3], instead of the power generation following the load demand as in the case of traditional power systems.

To achieve this new control paradigm, demand-side management approaches have been investigated. They can be broadly summarized as: (i) Scheduling of delay-tolerant power demand tasks [4-6] (ii) Real-time pricing [7-9], (iii) Use of energy storage to alleviate peak demands [10] and (iv) Direct load control or on-off control of smart loads [11-13]. Approaches (i) and (ii) can be used to shape the load profile in a pre-determined manner. But they cannot cope with instantaneous imbalance of power generation and load demand. Approach (iii) can help achieve instantaneous power balance, but energy storage has limited capacity and is an expensive option. Approach (iv) can achieve instantaneous power balance, but is intrusive to the consumers. Moreover, approaches (iii) and (iv) often require remote communication to coordinate the action of multiple smart loads and/or energy storage which could be unreliable.

A novel concept of "electric springs" has recently been proposed as a new technology [14], [15] to satisfy the new control paradigm of load demand following power generation for future smart grid with substantial penetration of distributed renewable energy sources. Based on the 3-century old Hooke's law, the mechanical spring concept has been extended to the electrical regime. Electric spring has been practically realized using a reactive power controller with an input-voltage control. Since electric springs are designed to support the ac mains voltage at various points of their installations across the power grid, it is imperative to derive a common control scheme so that they can support the voltage at their locations with consideration for the voltage variations along the distribution lines. In this paper, the droop control concept is applied to the electric spring control so that they can derive their own reference voltages according to their points of installation in the distribution network. Three practical $1 \mathrm{kVA}$ electric springs have been tested individually and in a group. The proposed droop control has been found to be effective in automatically coordinating the electric springs to act in a complimentary fashion without requiring central control and remote communication. 


\section{II.USE OF REACTIVE POWER CONTROLLERS AS ELECTRIC SPRINGS}

Shunt and series reactive power controllers have been adopted in several forms for applications in power systems [16][17]. In traditional uses of series reactive power controllers for voltage regulation, the output voltage of the power controller is usually regulated. Such "output voltage control" is common and its control scheme is illustrated in Fig.1(a) for series reactive power compensation in which the output voltage $V_{o}$ is regulated to a reference voltage $V_{o}^{*}$ with the help of traditional "output feedback control".

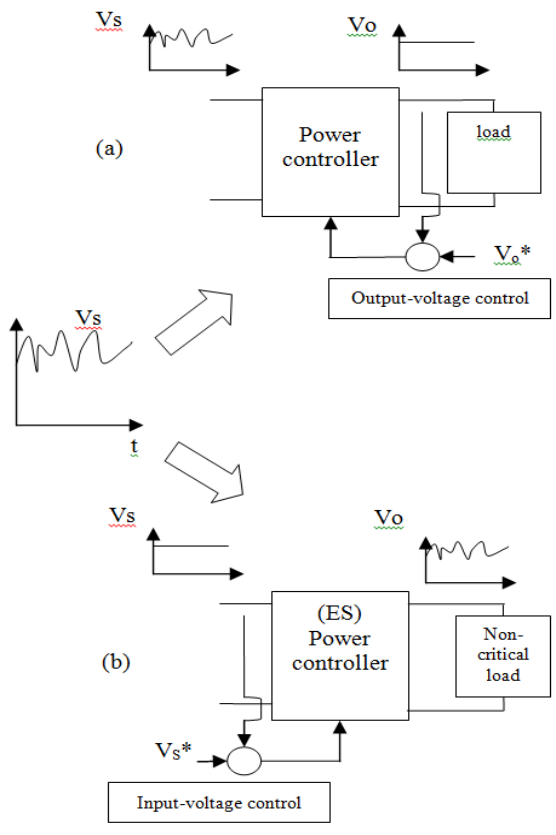

Fig.1 (a) Conventional output-voltage control in case of fluctuating ac mains and (b) new input-voltage control to stabilizing fluctuating ac mains.

It has recently been pointed out in [14], [15] that, if the "output voltage control of $V o$ " is changed to "input voltage control of Vs" as shown in Fig.1(b), such a subtle change in the control loop can offer novel features of the reactive power controller, which includes (i) the regulation of the input voltage Vs, (ii) the allowance for the output voltage $V o$ to fluctuate so that the load power in the output load $\left(R_{1}\right)$ can follow the power profile available from the ac power source (the mains). Since the reactive power controller with input voltage control can provide voltage support for the ac mains, it is called "voltage spring" or "electric spring". The main difference of the traditional output control for voltage support (Fig.1(a)) can be compared with the input voltage control for the electric spring (Fig.1(b)). It can be seen that the input voltage of the reactive power controller in Fig.1(b) (i.e. the electric spring) is regulated, while the output voltage of the traditional use of reactive power controllers in Fig.1(a) is regulated.

Even though the inverter structure and functions of the electric spring is similar to the conventional reactive power compensators (CRPC), the concept and operating principle are totally different. Using series CRPC as an example, the control parameters at the load side such as output voltage/current/power are used. One of the objective functions of series CRPC is to regulate the (output) load voltage/power, therefore the power generation has to follow the load demand. Conversely, an electric spring uses generation-side parameters such as mains voltage as the control variable. By regulating the generation-side voltage and letting the non-critical load voltage to fluctuate dynamically, the electric spring would provide voltage regulation and automatically shape the load power (load following) to follow the power generated. The requirement of installing an electric spring with a non-critical load (Fig.2) is also different from that of a CRPC.

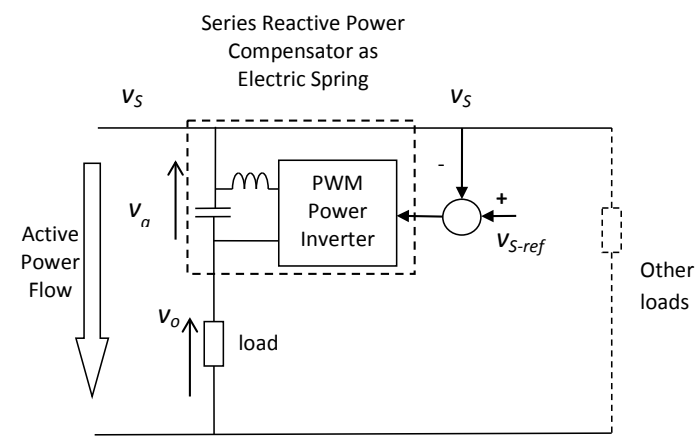

Fig.2 Simplified control schematic of series reactive power compensator as an electric spring (Input voltage $v_{s}$ regulated)

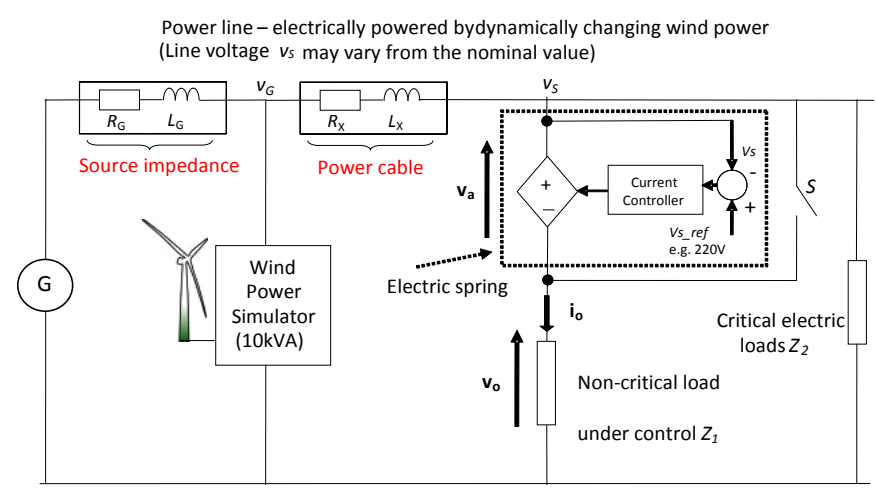

Fig.3 Schematic of an electric power system with an electric spring connected in series with a dissipative electric load $Z_{1}[[15]$

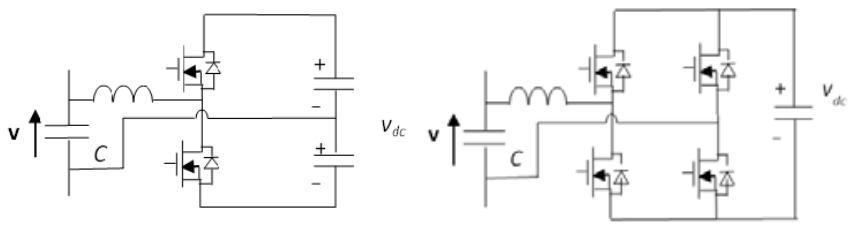

$\begin{array}{ll}\text { (a) Half-bridge inverter } & \text { (b) Full-bridge inverter }\end{array}$

Fig.4 Examples of the power inverters based on (a) half-bridge and (b) fullbridge inverters (for single-phase applications)

To illustrate these features of such an electric spring, the example used in [15] is used (Fig.3). For a single-phase system, half-bridge or full-bridge power inverter (Fig.4) can be used as the reactive power compensator. An output LC filter is used to reduce the switching harmonics so that a variable electric spring voltage $v_{a}$ can be generated to regulate the mains voltage $v_{s}$. 
The aim of the electric spring in the application example of Fig. 3 is to regulate $v_{s}$ to the nominal value of the mains voltage $v_{s_{-} r e f}$. Let $P_{\text {in }}$ be the sum of the base power generated by the ac generator and the dynamically-changing wind power. The general power balance equation for the system in Fig. 3 is:

$$
\begin{aligned}
& P_{\text {in }}=\left(\frac{v_{o}}{Z_{1}}\right)^{2} \operatorname{Re}\left(Z_{1}\right)+\left(\frac{v_{s}}{Z_{2}}\right)^{2} \operatorname{Re}\left(Z_{2}\right) \\
& P_{\text {in }}=P_{1}+P_{2}
\end{aligned}
$$

where $v_{o}$ and $v_{s}$ represent the rms values of the non-critical load and the mains voltage, respectively; $\operatorname{Re}(Z)$ is the real part of $Z$ that represents the resistive element $R ; Z_{1}$ is the impedance of the "non-critical" load and $Z_{2}$ is the impedance of the "critical" load; $P_{1}$ and $P_{2}$ are the power consumptions in the non-critical load and critical load, respectively. The use of an individual electric spring for resistive, inductive and capacitive non-critical loads has been addressed in [22]. It has been proven that the non-critical loads are not restricted to pure resistive loads only. Moreover, the operation of an ES does not require the presence of critical loads. In fact, a noncritical load with an embedded electric spring can be considered as a smart load which can be operated as an individual appliance.

This power balancing function of the electric spring becomes obvious if $Z_{1}$ and $Z_{2}$ are considered as pure resistive loads $R_{1}$ and $R_{2}$ respectively. The scalar equation (1) will become:

$$
\begin{aligned}
& P_{\text {in }}=\frac{v_{s}^{2}-v_{a}^{2}}{R_{1}}+\frac{v_{s}^{2}}{R_{2}} \\
& P_{\text {in }}=P_{1}+P_{2}
\end{aligned}
$$

where $v_{a}$ is the rms value of the electric spring.

If $v_{s}$ is kept constant by the electric spring, the only variable on the right-hand side of (2) is the rms electric spring voltage $v_{a}$. Critical load power $P_{2}$ is a constant. The variation of $v_{a}$ will adjust $P_{1}$ so that the sum of $P_{1}$ and $P_{2}$ will follow the profile of $P_{\text {in }}$ as shown in Fig.5. In other word, the electric spring allows the load power consumption to automatically follow the power generation - which is the new control paradigm required by future power systems with substantial intermittent renewable energy sources [1].

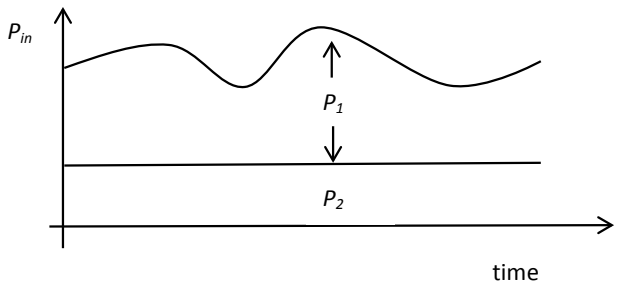

Fig.5 Power profiles of non-critical load $\left(P_{1}\right)$ and critical load $\left(P_{2}\right)$ when the mains voltage $v_{s}$ is regulated by the reactive power controller

The scalar equation for electric spring voltage vector $v_{a}$ under the capacitive mode and inductive mode is:

$$
v_{a}=\left\{\begin{array}{cl}
-v_{c} & \text { for capacitive mode } \\
+v_{c} & \text { for inductive mode }
\end{array}\right.
$$

where $v_{c}$ is the voltage of the filter capacitor of the power inverter.

The use of one reactive power controller as an electric spring, associated with a resistive non-critical load [15] and with resistive/inductive/capacitive loads [22] to support the mains voltage has been practically demonstrated. However, a single constant reference $V_{s_{-} \text {ref }}\left(\right.$ or $\mathrm{v}_{\mathrm{s}}{ }^{*}$ ) is not appropriate in the control loop with when a group of electric springs are used together in the distribution network. New control scheme is needed so that that the electric springs can work together when they are distributed across a power system.

\section{Parallel Operation \& Control of Distributed ELECTRIC SPRINGS}

\section{A Problem involved in parallel operation of electric springs}

Electric springs can be used to support the operation of future power grids with substantial penetration of intermittent renewable energy sources. They can be embedded into electric appliances such as electric water heaters, refrigerators and road lighting systems, and would therefore, be distributed over the power grid. Unlike conventional reactive power controllers that are installed in specific (or centralized) locations, electric springs, due to their embedment in non-critical loads, provide distributed reactive power compensation at the locations where the load power is consumed in the distribution network. These are suitable "non-critical loads" that can work with a variable mains voltage. Fig.6 shows an example of several electric loads connected along a distribution line. Due to the gradual voltage drop along a distribution power line (i.e. voltage drops across the impedance of the cables), the mains voltage levels at different points along its length are not identical. Generally, the mains voltage is highest at the power supply source and decreases gradually towards the end of the distribution line. For example, if a power transformer supplies electricity to many houses in a residential area, the mains voltage nearest the transformer may be $230 \mathrm{~V}$ (which is the nominal voltage) and that farthest from the transformer would be lower than $230 \mathrm{~V}$ (e.g. 210V), because of the voltage drop along the distribution feeder. That it, it is natural that $\mathrm{v}_{\mathrm{s} 1}>$ $\mathrm{v}_{\mathrm{s} 2}>\ldots>\mathrm{v}_{\mathrm{sn}}$.

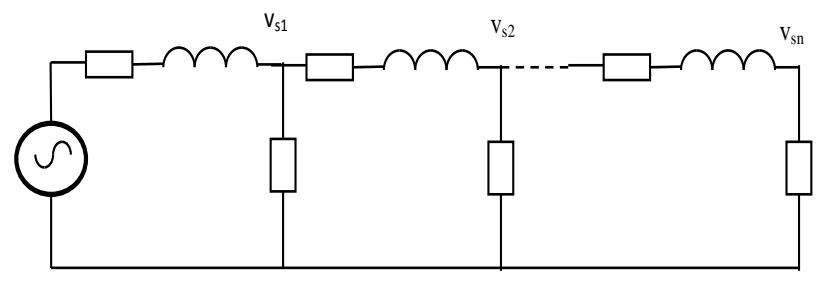

Fig.6 Gradual voltage drop along a distribution feeder with $\mathrm{v}_{\mathrm{s} 1}>\mathrm{v}_{\mathrm{s} 2}>$.. $>\mathrm{v}_{\mathrm{sn}}$

It should however be noted that this gradual reduction of mains voltage along the power cables is normal. However, this natural phenomenon of gradual voltage change along the transmission lines implies that the use of a "single" value of the reference voltage $\mathrm{v}_{\mathrm{s}}{ }^{*}$ for many electric springs is not practical. In practice, the reference voltage $\mathrm{v}_{\mathrm{s}}{ }^{*}$ values of the electric springs should not be set to an identical value, because the actual mains voltage rms values that electric springs need 
to regulate or support are location-dependent. If the same voltage reference $\mathrm{v}_{\mathrm{s}} *$ (e.g. $\mathrm{v}_{\mathrm{s}}{ }^{*}=220 \mathrm{~V}$ ) is set in all electric springs, they cannot work together because the mains voltage cannot have the same voltage values along the cables. Therefore, it is imperative that a control scheme should be implemented in such a way that the voltage reference $\mathrm{v}_{\mathrm{s}}$ * values should be automatically adjustable to suit the actual mains voltage values at the specific locations of the electric loads in which the electric springs are embedded.

\section{B Basic operation of electric springs}

Before explaining the control scheme, the basic power electronic circuit of the reactive power controller is first described. Fig.4 shows the circuits of the full-bridge power inverter and half-bridge power inverter that can be used as the main power circuit. The diodes behave like a diode rectifier through which the dc capacitor can be charged to provide the DC voltage source for the power inverter. By controlling the modulation index $(M)$ of the pulse-width-modulated (PWM) inverter, high-quality PWM voltage waveform at the mains frequency can be generated. With the use of the low-pass filter comprising an inductor and a capacitor, a sinusoidal voltage $\left(v_{a}\right)$ with controllable magnitude according to the control of the modulation index $(M)$ at the mains frequency can be generated as the output of the LC filter, which is also the voltage provided by reactive power controller (referred to as "electric spring" hereafter). In addition, the phase relationship of $\mathrm{v}_{a}$ with respect to $\mathrm{v}_{s}$ can be controlled. In order to ensure that the power inverter acts as a purely reactive power controller, the vector of the current through the electric spring and the vector of the voltage across the electric spring should be ideally perpendicular to each other.

\section{Implementation of droop control for automatically} adjustable mains voltage reference

Droop control is not new and has been used previously in parallel operation of power generators [18], [19] and gridconnected power inverters [20], [21]. Since the electric springs are reactive power controllers which theoretically do not handle active power, their behaviors are different from electric generators and power inverters, both of which handle both active and reactive power. In particular, it will be shown that the use of droop control can help a group of electric springs to work together in a coordinated manner in reactive power compensation and voltage regulation without any communication among the electric springs.

For the electric spring voltage control, the relationship between the modulation index and the spring voltage can be graphically illustrated in Fig.7, in which the x-axis refers to the modulation of the PWM voltage, which is effectively an indication of the magnitude of the filtered sinusoidal voltage waveform generated by the electric spring. In physical terms, the capacitive and inductive modes can be represented as a reference to the reactive power $\mathrm{Q}$ provided by the electric spring as shown in Fig.8. Here, when the electric spring provides negative reactive power, it provides voltage support (i.e. positive $\mathrm{V}_{\mathrm{a}}$ ). When it provides positive $\mathrm{Q}$, it generates negative $\mathrm{v}_{\mathrm{a}}$.

Due to the facts that (i) these electric springs will be distributed and installed in different locations along the transmission lines and (ii) the exact mains voltage reference values that these electric springs need to maintain as their respective reference values are location-dependent and therefore not identical. As shown in Fig.9, the reference mains voltage for the electric spring installed immediately next to the ac voltage source (that may come from a step-down transformer) is Vs*. For an electric spring installed at a distance $\mathrm{x}$ from the ac voltage source, the mains voltage reference may drop to Vsx*. For a further installation at the end of the transmission line (i.e. distance $n$ ) from the ac voltage source, such mains voltage reference will be reduced to a lower value Vsn*. Therefore, the voltage droop characteristics of these three electric springs are similar in nature, but different in values of the mains voltage references as indicated in Fig.10 and Fig.11.

In order to enable each electric spring to produce an automatically adjustable mains voltage reference value Vsx* for a nominal mains voltage Vs* (e.g. 230V), a new control scheme that can be implemented on the control board of each electric spring is proposed here. The basic concept is illustrated by the schematic of control block as shown in Fig.12 as an example. It should however be stressed that other control blocks with the same control objectives can also be used. The control scheme can be implemented in analogue or digital form, or a combination of both.

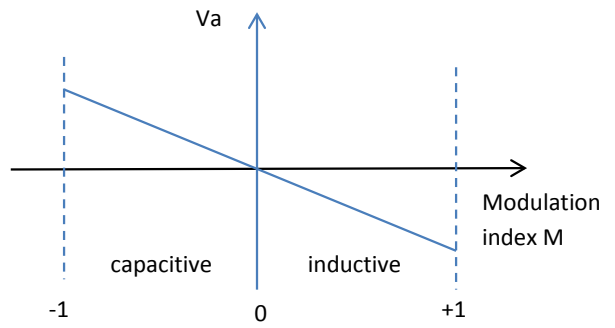

Fig.7 Operating modes of reactive power controller as an electric spring (Electric spring voltage $\mathrm{v}_{\mathrm{a}}$ as a function of modulation index $M$ )

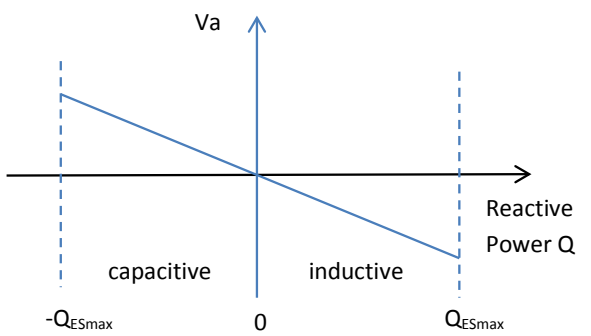

Fig.8 Operating modes of reactive power controller as an electric spring (Electric spring voltage $\mathrm{v}_{\mathrm{a}}$ as a function of reactive power $\mathrm{Q}_{\mathrm{ESmax}}$ provided the electric spring)

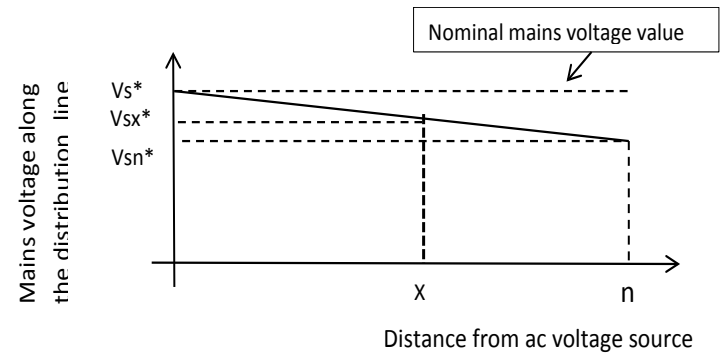

Fig. 9 Gradual reduction of mains voltage along a distribution line 


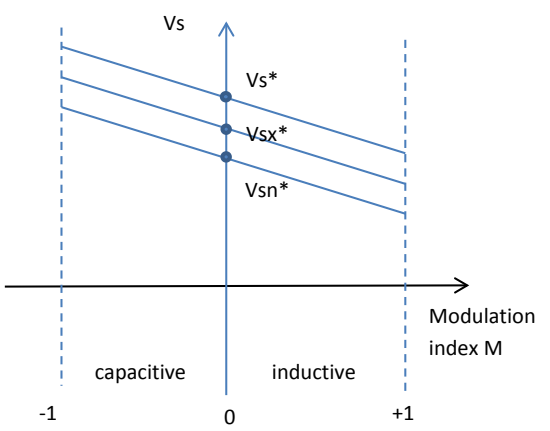

Fig. 10 Ideal characteristic of electric springs located in different positions along the distribution line

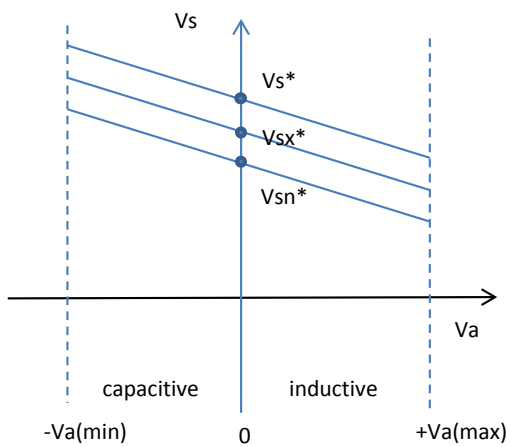

Fig. 11 Ideal characteristic of electric springs located in different positions along the distribution line

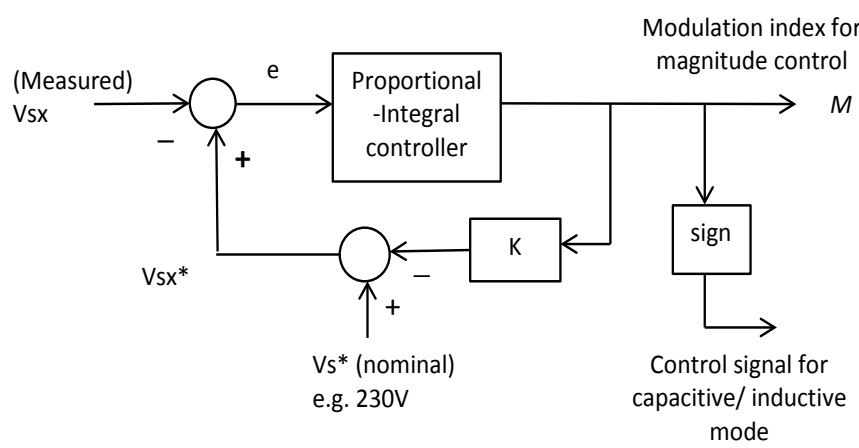

Fig.12 Proposed control scheme for providing an automatically adjustable reference voltage "Vsx_ref".

Without loss of generality, the electric spring is assumed to be installed at a distance $\mathrm{x}$ from the ac voltage source which has a "nominal" mains voltage $\mathrm{v}_{\mathrm{s}} *$ (e.g. $230 \mathrm{~V}$ or $\left.110 \mathrm{~V}\right)$. This electric spring is connected to the mains voltage at which the actual (measured) mains voltage is $\mathrm{v}_{\mathrm{sx}}$. The aim of the proposed control scheme is to generate an adjustable reference voltage $\mathrm{v}_{\mathrm{sx}}{ }^{*}$, which corresponds to the actual mains voltage at location- $x$ of the distribution lines. The measured $\mathrm{V}_{\mathrm{sx}}$ is subtracted from the $\mathrm{v}_{\mathrm{sx}}{ }^{*}$ and the difference or error signal $e$ is fed to a proportional-integral (PI) controller. The output of the PI control is the modulation index $(M) . M$ is fed to a gain $\mathrm{K}$ and the signal $M K$ is subtracted from the nominal mains voltage $\mathrm{v}_{\mathrm{s}} *$ to form the generated adjustable mains voltage reference $\mathrm{v}_{\mathrm{sx}} *$. The polarity of $M$ provides a control signal for the capacitive mode or inductive mode of operation.

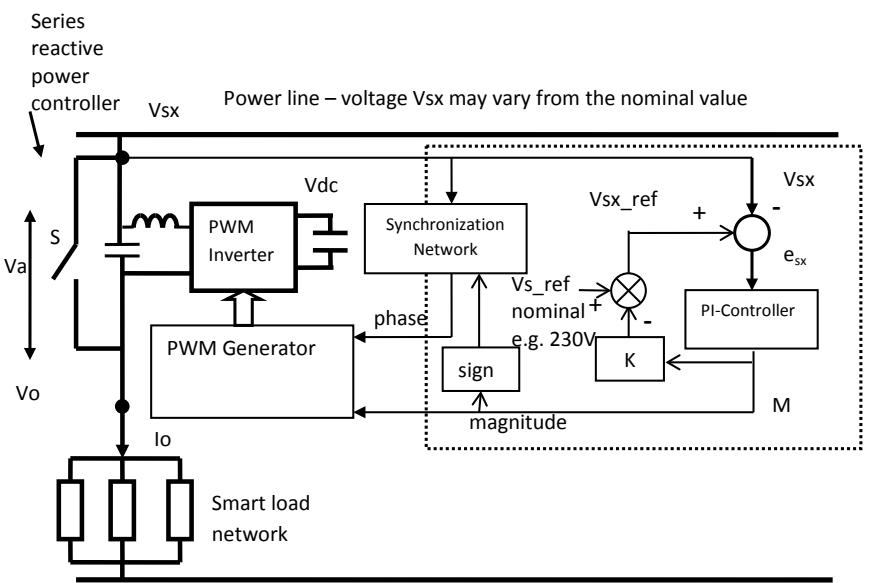

Fig.13 New control scheme for electric springs [enclosed in dotted box], where $\mathrm{v}_{\mathrm{sx}}$ is the measured mains voltage at the location of the electric spring and $\mathrm{v}_{\mathrm{sx} \_ \text {ref }}$ is the automatically adjustable mains voltage reference at the location of $\mathrm{v}_{\mathrm{sx}}$.

The principle of the control scheme can be illustrated with the following control equations:

$$
\begin{array}{r}
v_{S X} *=v_{S} *-M K \\
e=\left(v_{S} *-M K\right)-v_{S X}
\end{array}
$$

Equation (5) indicates that the adjustable mains voltage reference $\mathrm{v}_{\mathrm{sx}}{ }^{*}$ depends on the droop characteristic which is represented by the constant gain $\mathrm{K}$. Since $M$ is a variable, the $-M K$ term on the right-hand side allows this reference voltage to be adjusted. Since the function of the PI-controller is to keep the error signal (e) to zero, equation (6) shows that the operation of the control scheme is to force the measured $\mathrm{v}_{\mathrm{sx}}$ to approach the automatically adjustable reference $\mathrm{v}_{\mathrm{sx}}{ }^{*}$. The equation for the modulation index $M$ is:

$$
M=k_{P}(e)+k_{I} \int(e) d t
$$

where $k_{P}$ is the proportional coefficient and $k_{I}$ is the integral coefficient of the PI controller. Therefore, a novel control scheme indicated in the dotted box of Fig.13 is proposed.

\section{EXPERIMENTAL VERIFICATION}

In order to practically confirm the effectiveness of the new control scheme for the electric springs, an experimental setup shown in Fig.14 has been used for tests in the Maurice Hancock Smart Energy Laboratory at Imperial College London. The setup simulates a power transmission line system fed by both conventional ac generator and a disturbance source mimicking intermittent renewable energy sources. Electric loads and their respective electric springs are connected at 3 different points of the distribution line with slightly different mains voltage levels. 


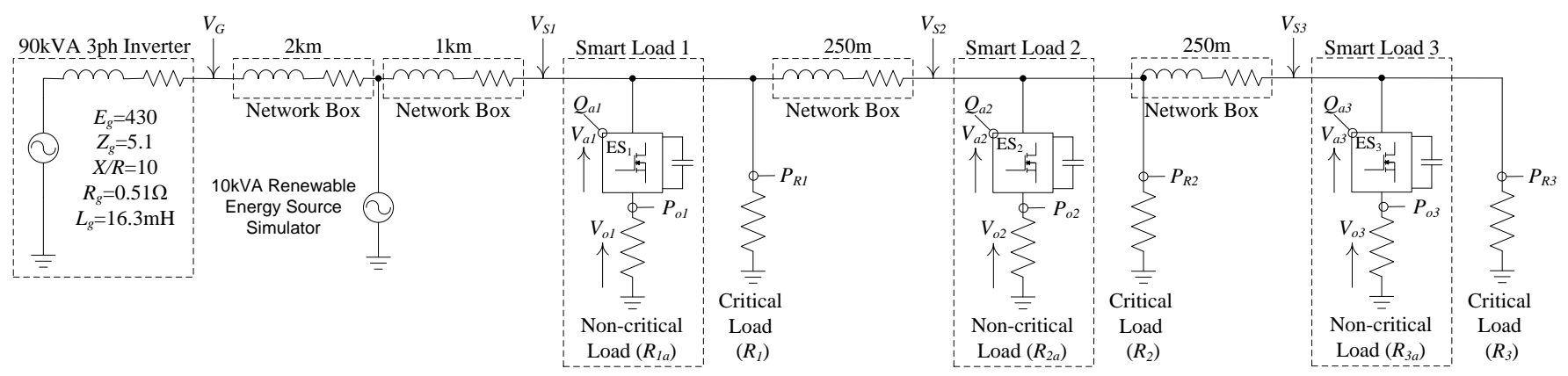

Fig.14 Single phase diagram of the experimental setup of the power grid and loads (with 3 distributed electric springs working as a group).

In practice, there should not be any specific restrictions on the locations of the electric springs (which are embedded in non-critical loads such as water heaters and refrigerators and should operate independently as smart loads). Here, a 90KVA inverter is used to represent the ac power generator to provide a stable ac power supply with a nominal mains voltage of $220 \mathrm{~V}$ at $50 \mathrm{~Hz}$. An $10 \mathrm{kVA}$ power inverter is used to inject dynamically changing reactive power (according to a prerecorded profile of 720s) to the power grid to create voltage fluctuation in order to produce a weakly regulated mains voltage as shown in Fig 15a. Three electric springs are constructed by modifying 3 commercial power inverter products with new control interfaces for the 'input voltage control'. In practice, the reactive power capacity of an electric spring should be small (e.g. setting at a maximum of 0.22 $\mathrm{kVA}$ in the experiments), because the grid voltage support should be provided by many "distributed low-capacity" electric springs over the grid instead of using a few "centralized high-capacity" ones. The system parameters used in the experimental setup are shown in Appendix.

Fig 15a shows the mains voltage of the system. This diagram can be divided into three sections.

1. $0-720 \mathrm{~s}$ : Without activating the electric springs, the recorded reactive power profile of the $10 \mathrm{kVA}$ power inverter creates the voltage fluctuation in the power grid in order to simulate a weakly regulated mains voltage.

2. 720 - 1440s: With the reactive power profile of the $10 \mathrm{kVA}$ power inverter repeated, the electric springs are activated without the proposed droop control.

3. $1440-2160$ s: With the reactive power profile of the $10 \mathrm{kVA}$ power inverter repeated again, the electric springs are activated with the proposed droop control.

In the first section of Fig.15a (i.e. 0 - 720s), it can be seen the mains voltage fluctuation is quite substantial. The injection of fluctuating reactive power by the $10 \mathrm{kVA}$ power inverter does create variations in the mains voltage level. With the electric springs activated without the proposed droop control scheme, the mains voltage seems to be stable. But it will be shown later that the operations of the three electric springs are not functioning in a harmonious manner without using the proposed droop control scheme.

Fig.15b and Fig.15c show a portion of the mains voltage levels at the 3 locations of the loads along the transmission line without and with the electric springs activated, respectively. It can be seen that the mains voltage level at the load location closer to the voltage source are higher than that further away from the voltage source due to the gradual voltage drop along the distribution line. Consequently, $\mathrm{v}_{\mathrm{s} 1}>$ $\mathrm{v}_{\mathrm{s} 2}>\mathrm{v}_{\mathrm{s} 3}$. These measurements confirm that the voltage references for the 3 electric springs at three different locations are not identical.

The problem of the three electric springs without the proposed droop control can be seen in Fig.16 in which their dynamic reactive power outputs are recorded. In the first section from 0s to 720s, the 3 electric springs are inactive and so they generate zero reactive power. In the second section without using the proposed control scheme, it is important to note that electric spring 1 provides maximum positive reactive power (i.e. maximum and positive Qa1), meaning that electric spring 1 is operating in its inductive mode to "suppress" its mains voltage $\mathrm{v}_{\mathrm{s} 1}$. This operation can be understood from the instantaneous $\mathrm{v}_{\mathrm{s} 1}$ which stays over the nominal value of $220 \mathrm{~V}$ in Fig.15b. At the same time, it is noted that electric spring 3 operates mainly in the capacitive mode by generating primarily negative reactive power (i.e. maximum negative reactive power Qa3) to support the mains voltage $\mathrm{v}_{\mathrm{s} 3}$. This action can be understood from the instantaneous value of $\mathrm{v}_{\mathrm{s} 3}$ which stays below the nominal voltage of $220 \mathrm{~V}$ in Fig.15b. Therefore, it can be seen that electric spring 1 and electric spring 3 "work against" each other (i.e. not cooperating), instead of "cooperating with" each other. The action of electric spring 2 fluctuates between the two extremes.

Even under such inharmonious operations, the electric springs "without the proposed droop control" scheme can still regulate the mains voltage although some of them fight against each other. The reason is simply that the reactive power capacities of the electric springs in this special case are sufficient to compensate the reactive power required for the voltage regulation in the setup. However, in practice, the reactive power capacities of the electric springs may be much smaller in order to reduce costs. So it is imperative that these electric springs should work in unison with each other in an orchestrated manner.

The third section of Fig.16 shows how these electric springs can work "with" one another when the proposed control scheme is used. Under such scheme, all the three electric springs generate reactive power in a similar manner to compensate the voltage fluctuation. This means that they are "co-operating" rather than fighting each other. Similar argument can be made from the measured modulation indices of the three electric springs in Fig.17. Electric spring 1 and electric spring 3 are fighting each other before the proposed control scheme is used. Once the proposed control scheme is 
used, all electric springs work together in harmony. These measurements confirm that the proposed control scheme enables electric springs to regulate the mains voltage levels at their respective locations of the transmission line.

The proposed control scheme allows them the work with one another in a co-operative manner. The significance is that even individual electric springs may have limited reactive power capacities, the proposed control scheme enables them to work together in order to maximize their effects for reactive power compensation, which is an effective means to provide voltage regulation in power grid. While traditional reactive power controllers provide reactive power compensation only, the extra "non-critical load variation" function of the electric springs offers automatic power flow control which will bring extra benefits to frequency control.

Fig.18 shows the power of the critical load in the 3 sections. It can be seen that the electric springs can stabilize the mains voltage so that the power consumed by the critical load remains fairly stable. The automatic generation of the electric spring voltages will alter the voltage levels across the three non-critical loads as shown in Fig.19. It can be seen that the voltage levels of the three non-critical loads "without using the proposed control" in the second section of Fig.19 are wide apart. But after using the proposed control scheme, their differences are minimized, meaning that the load change is better distributed among the non-critical loads. The noncritical load power measurements are included in Fig.20. In the first section, the non-critical load power values vary with the fluctuating mains voltage. The averaged non-critical powers are reduced in both the second section (with electric springs activated without the proposed control scheme) and the third section (with electric springs activated with the proposed control scheme). However, the load shedding is highly even when the proposed control scheme is not used). When the proposed scheme is used, the load shedding is much evenly distributed among the non-critical loads.

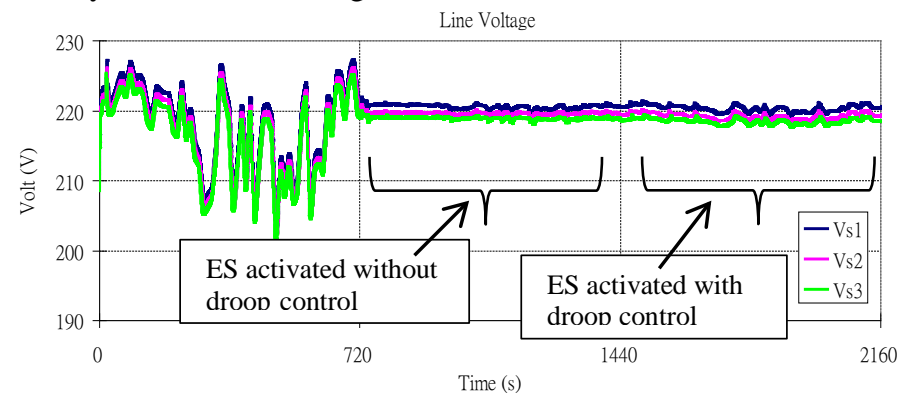

Fig.15a Measured rms values of the mains voltage $V_{S 1}, V_{S 2} \& V_{S 3}$.

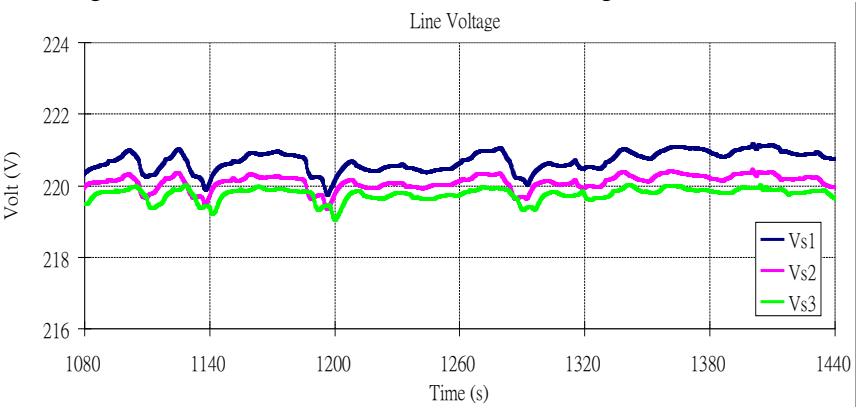

Fig.15b Measured root-mean-square values of the mains voltage $V_{S 1}, V_{S 2}$ and $V_{S 3}$ from 1080 to 1440 sec (ES activated without the proposed droop control).

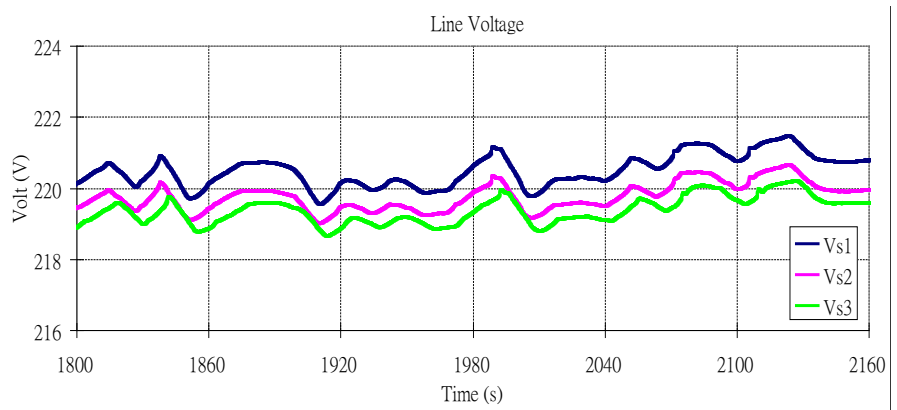

Fig.15c Measured root-mean-square values of the mains voltage $V_{S 1}, V_{S 2}$ and $V_{S 3}$ from 1800 to 2160 sec (ES activated with the proposed droop control).

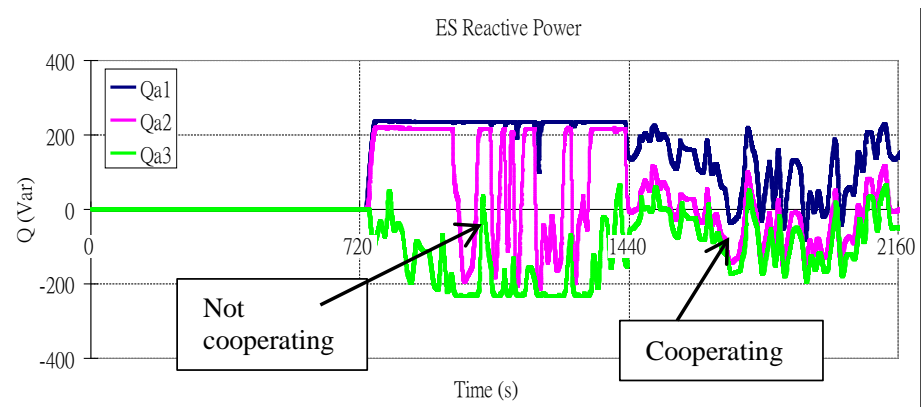

Fig.16 Measured average value of reactive power generated by the 3 electric springs $\left(Q_{a 1}, Q_{a 2}\right.$ and $\left.Q_{a 3}\right)$.

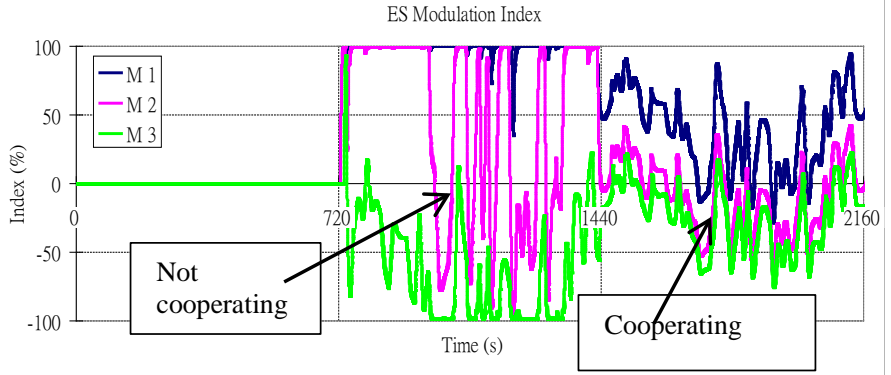

Fig. 17 Measured modulation indices of the electric springs $M_{1}, M_{2}$ and $M_{3}$.

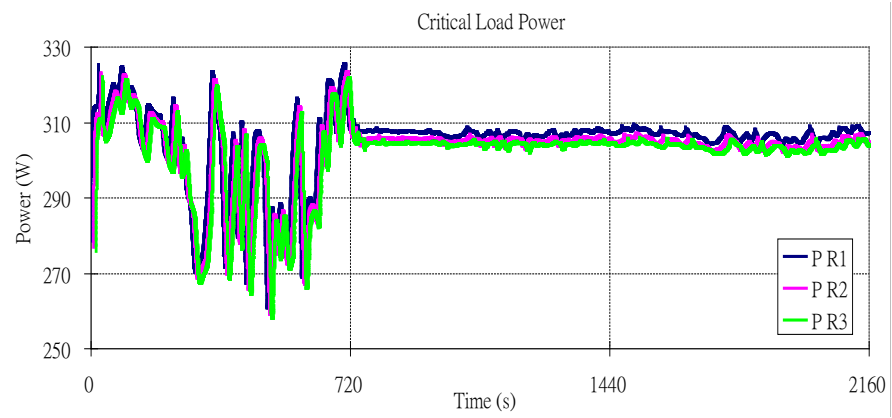

Fig.18 Measured average value of the critical load power $P_{R 1}, P_{R 2}$ and $P_{R 3}$.

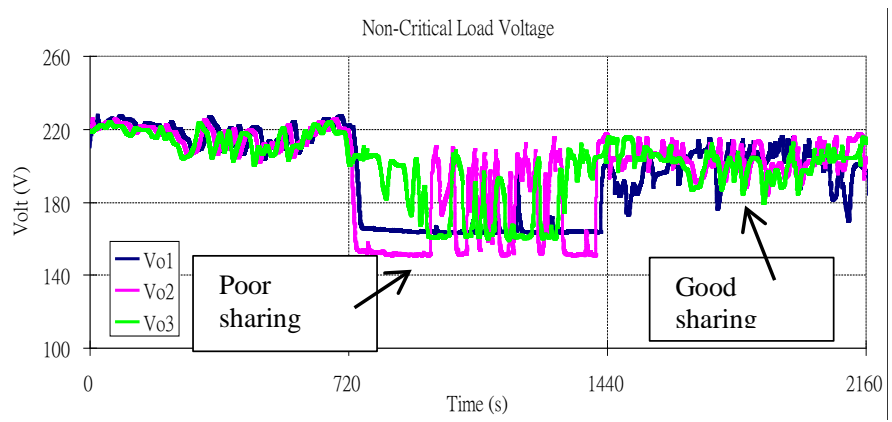

Fig. 19 Measured root-mean-square values of the non-critical load voltage $V_{o 1}, V_{o 2}$ and $V_{o 3}$. 


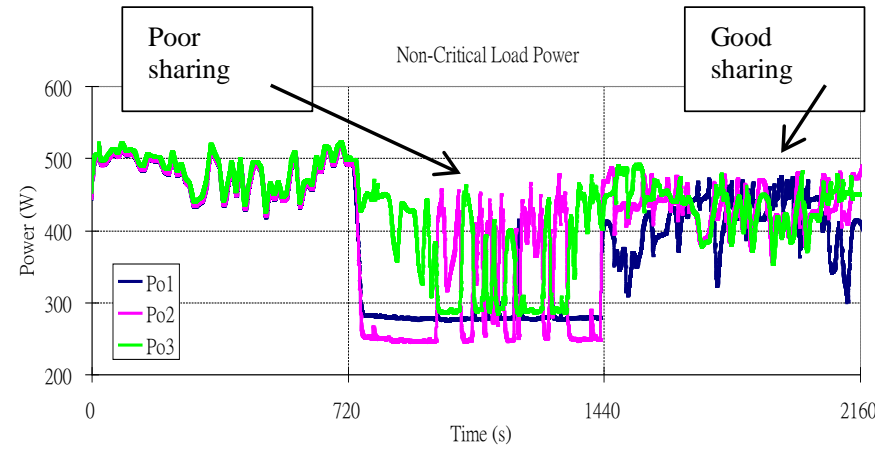

Fig.20 Measured average value of the non-critical load power $P_{o 1}, P_{o 2}$ and $P_{\text {оз. }}$.

\section{CONCLUSION \& DisCUSSION}

A control scheme has been successfully developed and implemented for a group of electric springs. It enables individual electric springs to generate their mains voltage reference values according to their installation locations in the distribution lines and to work in co-operative manner, instead of fighting against one another, therefore allowing the electric springs to work in group to maximize their reactive power compensation effects for voltage regulation. The control method also leads to more evenly distribution of load power shedding among the non-critical loads. The attractive features of the control scheme have been successfully verified in an experimental smart grid setup.

With the droop control scheme, many electric springs of small VA ratings could be embedded into non-critical loads such as electric water heaters and refrigerators to form a new generation of smart loads that are adaptive to power grid with substantial penetration of renewable energy sources of distributed and intermittent nature. If many small electric springs are deployed in the power grid in a distributed manner, their collective voltage stabilizing efforts can be added together. Because the electric springs allow these smart loads to consume power following the varying profile of intermittent renewable energy sources, they have the potential to solve the stability problems arising from the intermittent nature of renewable energy sources and ensure that the load demand will follow power generation, which is the new control paradigm for future smart grid. Since the electric appliances embedded with the electric springs can share load shedding automatically, this approach should be more consumerfriendly when compared with the on-off control of electric appliances. For example, shutting down refrigerators is intrusive and inconvenient to the consumers (and may involve consumers' rights issues) and requires some forms of central control. Allowing many smart refrigerators to shed some load without being noticed and central control is more consumerfriendly.

The individual operations of the electric springs have previously been evaluated. The successful implementation of the droop control for 3 electric springs working as a group in a small distributed network in this study is a just a step forward to confirm that multiple electric springs can work together without ICT technology. The collective effects of electric springs and their capacity are new topics that deserve further investigations. Extensive simulation studies are needed to confirm the effectiveness of many such electric springs working together in a large-scale power system model.

\section{APPENDIX}

For the control loops:

Droop gain $=1$

AC loop: $\mathrm{K}_{\mathrm{p}}=40 ; \mathrm{K}_{\mathrm{p}} \mathrm{xT}_{\mathrm{s}} / \mathrm{T}_{\mathrm{i}}=20$

DC loop: $\mathrm{K}_{\mathrm{p}}=20 ; \mathrm{K}_{\mathrm{p}} \mathrm{xT} / \mathrm{T} / \mathrm{T}$

where $K_{p}$ is the proportional gain, $T_{s}$ is the sampling time (20ms), and $T_{i}$ is the integral time constant.

\begin{tabular}{|c|c|}
\hline Inverter Topology: & Single Phase Half Bridge Inverter \\
\hline Switching Frequency: & $20 \mathrm{kHz}$ \\
\hline Regulated DC-Bus Voltage: & $400 \mathrm{Vdc}$ \\
\hline DC Bus Capacitance: & $\mathrm{C} 1=3000 \mu \mathrm{F}, \mathrm{C} 2=3000 \mu \mathrm{F}$ \\
\hline Inverter Output Voltage Range: & $\begin{array}{c}0 \sim 134 \text { Vac, } \\
\text { Controlled by the Modulation } \\
\text { Index }(M)\end{array}$ \\
\hline Power MOSFET: & $\begin{array}{l}\text { IRFP31N50L } \\
\end{array}$ \\
\hline Typical R $\mathrm{DS}_{\text {(on) }}$ : & $0.15 \Omega @ \mathrm{I}_{\mathrm{D}}=31 \mathrm{~A}$ \\
\hline \multicolumn{2}{|l|}{ Output Low Pass Filter: } \\
\hline Measured Inductance: & 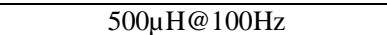 \\
\hline $\begin{array}{r}\text { Measured Equivalent Series } \\
\text { Resistance: }\end{array}$ & $0.09 \Omega @ 100 \mathrm{~Hz}$ \\
\hline Capacitance: & $13.2 \mu \mathrm{F}$ \\
\hline
\end{tabular}

\begin{tabular}{|l|l|l|}
\hline \multicolumn{3}{|c|}{ Network Box } \\
\hline Distance & Resistance $(\Omega)$ & Inductance $(\mathrm{mH})$ \\
\hline $250 \mathrm{~m}$ & $0.1 \Omega$ & $0.61 \mathrm{mH}$ \\
\hline $1 \mathrm{~km}$ & $0.1 \Omega$ & $1.22 \mathrm{mH}$ \\
\hline $2 \mathrm{~km}$ & $0.1 \Omega$ & $2.4 \mathrm{mH}$ \\
\hline
\end{tabular}

\section{REFERENCES}

[1] P.P. Varaiya, F.F. Wu and J.W. Bialek, "Smart Operation of Smart Grid: Risk-Limiting Dispatch”, Proceedings of the IEEE, Volume: 99 , Issue: 1, 2011 , Page(s): 40 - 57.

[2] D. Westermann,; A. John, "Demand Matching Wind Power Generation With Wide-Area Measurement and Demand-Side Management", IEEE Transactions on Energy Conversion, Volume: 22 , Issue: 1, 2007 , Page(s): 145 - 149

[3] P. Palensky and D. Dietrich, "Demand Side Management: Demand Response, Intelligent Energy Systems, and Smart Loads", IEEE Transactions on Industrial Informatics, Volume: 7 , Issue: 3, 2011 , Page(s): 381 - 388

[4] A. Mohsenian-Rad, V.W.S. Wong, J. Jatskevich,; R. Schober; A. LeonGarcia,; "Autonomous Demand-Side Management Based on GameTheoretic Energy Consumption Scheduling for the Future Smart Grid", IEEE Transactions on Smart Grid, Volume: 1 , Issue: 3, 2010 , Page(s): 320 - 331

[5] M. Parvania and M. Fotuhi-Firuzabad, "Demand Response Scheduling by Stochastic SCUC", IEEE Transactions on Smart Grid, Volume: 1 , Issue: 1, 2010 , Page(s): 89 -98

[6] M. PedrasaT.D. , Spooner and I.F. MacGill, "Scheduling of Demand Side Resources Using Binary Particle Swarm Optimization", IEEE Transactions on Power Systems, Volume: 24 , Issue: 3, 2009 , Page(s): $1173-1181$

[7] A.J. Conejo, J.M. Morales and L. Baringo, " Real-Time Demand Response Model", IEEE Transactions on Smart Grid, Volume: 1 , Issue: 3, 2010 , Page(s): 236 - 242

[8] A.-H. Mohsenian-Rad and A. Leon-Garcia,; "Optimal Residential Load Control With Price Prediction in Real-Time Electricity Pricing Environments", IEEE Transactions on Smart Grid, Volume: 1 , Issue: 2, 2010 , Page(s): 120 - 133

[9] A.J. Roscoe and G. Ault, "Supporting high penetrations of renewable generation via implementation of real-time electricity pricing and 
demand response", IET Renewable Power Generation, Volume: 4 , Issue: 4, 2010 , Page(s): 369 - 382

[10] F. Kienzle P. , Ahčin; G. Andersson, "Valuing Investments in MultiEnergy Conversion, Storage, and Demand-Side Management Systems Under Uncertainty", IEEE Transactions on Sustainable Energy, Volume: 2 , Issue: 2, 2011 , Page(s): $194-202$

[11] S.C. Lee, S.J. Kim and S.H. Kim, "Demand Side Management With Air Conditioner Loads Based on the Queuing System Model", IEEE Transactions on Power Systems, Volume: 26 , Issue: 2, 2011 , Page(s): $661-668$

[12] G.C. Heffner, C.A. Goldman and M.M. Moezzi, "Innovative approaches to verifying demand response of water heater load control", IEEE Transactions on Power Delivery, Volume: 21 , Issue: 1, 2006, Page(s): 388 - 397

[13] A. Brooks, E. Lu, D. Reicher, C. Spirakis and B. Weihl, "Demand Dispatch", IEEE Power and Energy Magazine, Volume: 8 , Issue: 3, 2010 , Page(s): 20 - 29

[14] S.Y.R. Hui, C.K. Lee and F.F. Wu, "Power control circuit and method for stabilizing a Power Supply", PCT patent application 61/389,489, filed on 4 October 2010

[15] S.Y.R. Hui, C.K. Lee and F.F. Wu, "Electric springs - A new smart grid technology”, IEEE Transactions on Smart Grid, Vol.3, No.3, Sept. 2012, pp: 1552-1561.

[16] T.J. Miller, "Reactive Power Control in Electric Systems", John Wiley \& Sons 1982

[17] H. Fujita, Y. Watanabe and H. Akagi, "Control and analysis of a unified power flow controller", IEEE Transactions on Power Electronics, Volume: 14 , Issue: 6, 1999 , Page(s): 1021 - 1027

[18] J. Machowski, J. Bialek and J. Bumby, "Power system dynamics and stability”, Wiley, 1997, pp.21-25

[19] B.W. Weedy \& B.J. Cory, "Electric Power Systems", 4th Edition, New York, Wiley, 1998

[20] Po-Tai Cheng; Chien-An Chen; Tzung-Lin Lee; Shen-Yuan Kuo, "A Cooperative Imbalance Compensation Method for DistributedGeneration Interface Converters", IEEE Transactions on Industry Applications, Volume: 45 , Issue: 2, 2009 , Page(s): 805 - 815

[21] K. De Brabandere, B. Bolsens, J. Van den Keybus, A. Woyte, J. Driesen and R. Belmans, "A voltage and frequency droop control method for parallel inverters", IEEE Transactions on Power Electronics, Vol.22, No.4, July 2007, pp.1107-1115

[22] S.C. Tan, C.K. Lee and S.Y.R. Hui, "General steady-state analysis and control principle of electric springs with active and reactive power compensations", IEEE Transactions on Power Electronics, Volume: 28 , Issue: 8, 2013, Page(s): 3958 - 3969 